[Highlight]

\title{
溶液相中卤键驱动的超分子螺旋
}

\author{
刘鸣华
}

(国家纳米科学中心, 北京 100190)

\section{Halogen Bonding Driven Supramolecular Helix in Solution}

\author{
LIU Ming-Hua \\ (National Center for Nanoscience and Technology, Beijing 100190, P. R. China)
}
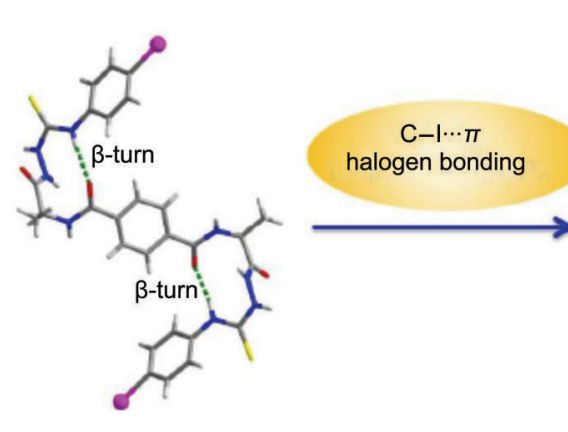

螺旋构象具有重要的生命科学研究价值, 如 DNA 双股螺旋和蛋白质 $\alpha$-螺旋是生命组成中两类 主要的螺旋结构。基于分子间非共价相互作用的 超分子螺旋作为仿生螺旋的一种, 因其结构可调控 性和动态可逆性特征而备受关注, 近年来已在不对 称催化、手性传感和分离、仿生材料等研究领域展 现重要的应用 ${ }^{1,2}$ 。

传统构造超分子螺旋的非共价相互作用主要 包括氢键、静电、 $\pi-\pi$ 堆积、亲疏水以及金属配位 等。卤键是存在于分子中卤素原子的亲电区域和 同一或另一分子之亲核区域间的非共价相互作用, 是类似于氢键的新型分子间相互作用。卤键已广 泛应用于晶体工程、手性拆分、分子识别、超分子组 装以及药物分子设计等研究领域 3 。然迄今为止, 基 于卤键的超分子螺旋仅有数例发现于晶体结构 中 $^{4,5}$, 溶液相中能否形成超分子螺旋尚未见报道。

最近厦门大学江云宝教授课题组发现了首例 溶液相中基于卤键驱动力的超分子螺旋, 相关结果 发表在Journal of the American Chemical Society 杂
志上 ${ }^{6}$ 。在溶液体系中, 分子间卤键作用需有足够强 度方能维持超分子螺旋结构, 同时还需避免分子间 其它弱相互作用的干扰。为此, 他们提出一种以卤 键为驱动力构造超分子螺旋的策略: 以具螺旋结构 的化合物为构筑基元, 在分子两端引入合适的卤键 给体和受体结构。他们以基于丙氨酸的双边 $N$-酰 胺基硫嫝为构筑基元, 并于分子两个末端苯环修饰 以对位卤素取代基, 成功地构建了溶液相首例单股 超分子螺旋。一方面, 存在于肽基 $N$-酰胺基硫脲中 的 $\beta$-转角提供螺旋片段 ${ }^{7}$; 另一方面, 卤代苯结构单 元可作为潜在的卤键给体和受体单元; 此外, 硫艮 结构可有效避免溶液中分子间氢键作用的干扰。 晶体结构显示碘取代分子可藉由分子间 $\mathrm{C}-\mathrm{I} \cdots \pi$ 卤 键作用形成首-尾连接的超分子螺旋链。吸收光谱、 圆二色 (CD) 光谱、动态光散射(DLS)、扫描电子显微 镜(SEM)、多维高场核磁等研究则表明碘取代分子 在乙腈溶剂中于微摩尔级别浓度下即已形成单股 超分子螺旋链。密度泛函理论(DFT)计算结果和对 照实验充分揭示构筑基元之螺旋结构 $\beta$-转角显著 
增强了分子间的 $\mathrm{C}-\mathrm{I} \cdots \pi$ 卤键作用, 进而促进超分 子螺旋的形成。值得指出的是, “多数法则” 实验显 示单股超分子螺旋呈现手性放大效应。这一研究 成果不仅开辟了卤键和超分子螺旋研究的新方向, 更为超分子螺旋之功能性材料的发展给出新思 路。该研究的高场多维核磁共振和 DFT 计算分别 得到中国科学院武汉数学物理研究所刘买利研究 员和厦门大学闽江学者讲座教授美国西密西根大 学莫亦荣教授的指导。

\section{References}

(1) Liu, M.; Zhang, L.; Wang, T. Chem. Rev. 2015, 115, 7304. doi: 10.1021/cr500671p

(2) Yashima, E.; Ousaka, N.; Taura, D.; Shimomura, K.; Ikai, T.;
Maeda, K. Chem. Rev. 2016, 116, 13752. doi: 10.1021/acs. chemrev.6b00354

(3) Cavallo, G.; Metrangolo, P.; Milani, R.; Pilati, T.; Priimagi, A.; Resnati, G.; Terraneo, G. Chem. Rev. 2016, 116, 2478. doi: 10.1021/acs.chemrev.5b00484

(4) Farina, A.; Meille, S. V.; Messina, M. T.; Metrangolo, P.; Resnati, G.; Vecchio, G. Angew. Chem. Int. Ed. 1999, 38, 2433. doi: 10.1002/(SICI)1521-3773(19990816)38:16<2433::AIDANIE2433>3.3.CO;2-4

(5) Lieffrig, J.; Niassy, A. G.; Jeannin, O.; Fourmigue, M. CrystEngComm 2015, 17, 50. doi: 10.1039/c4ce01935k

(6) Cao, J.; Yan, X.; He, W.; Li, X.; Li, Z.; Mo, Y.; Liu, M.; Jiang, Y. B. J. Am. Chem. Soc. 2017, doi: 10.1021/jacs.6b13171

(7) Yan, X. S.; Wu, K.; Yuan, Y.; Zhan, Y.; Wang, J. H.; Li, Z.; Jiang, Y. B. Chem. Commun. 2013, 49, 8943. doi: 10.1039/c3cc44336a. 